\title{
Influence of Size on Apparent Scrambling of Sequence During CID of $b$-Type Ions
}

\author{
Samuel Molesworth, Sandra Osburn,* and Michael Van Stipdonk \\ Department of Chemistry, Wichita State University, Wichita, Kansas, USA
}

We investigated the influence of peptide size on the apparent loss of sequence during collision-induced dissociation (CID) of $b$ ions using a group of peptides containing from between 4 and 10 residues. Although scrambling of sequence for $b_{3}{ }^{+}$generated from tetrapeptides is minimal, significant formation of nondirect sequence ions (i.e., ions for which scrambling has apparently occurred) was observed for all larger $b$ ions included in the study. (J Am Soc Mass Spectrom 2009, 20, 2174-2181) (C 2009 Published by Elsevier Inc. on behalf of American Society for Mass Spectrometry

$\mathrm{T}$ Tandem mass spectrometry (MS/MS) is the primary method used for peptide and protein identification in proteomics [1, 2]. Sequence identification can be made either de novo by interpretation of fragmentation patterns or with bioinformatics tools that use sequencing algorithms and models of peptide dissociation reactions. However, bioinformatics approaches [3] are hampered by the rudimentary fragmentation models used by sequencing programs, which may lead to invalid assignments of peptides and proteins [3, 4]. Implementation of more detailed peptide fragmentation mechanisms into these sequencing algorithms should lead to improved bioinformatics-based MS/MS sequencing.

Fragmentation of protonated peptides under lowenergy collision conditions typically involves charge (proton) mediated reactions, in which $b, y$, and $a$ ions are generated by cleavage of amide bonds [5, 6]. Extensive research has been focused on the energetics and kinetics of proton mobilization, which has led to the mobile proton model $[7,8]$ and its associated amide bond cleavage pathways [9-14]. The more recently introduced pathways in competition (PIC) fragmentation model [14] builds on the mobile proton model by including consideration of the structures and reactivity of the primary fragments.

The $\mathrm{N}$-terminal $b_{n}$-type fragment ions are thought to have a 5-membered oxazolone ring $[9,15]$ structure that maintains much of the sequence of the precursor peptide ion. However, recent experiments [16, 17] suggest that cyclization of the linear, oxazolone-terminated $b$ ions can occur to generate a macrocyclic $b$ ion isomer, which can then open at several different amide bonds to re-form linear, oxazolone-terminated ions with concomitant scrambling of the original primary sequence (Scheme 1). We refer to this type of process as $b$-type

Address reprint requests to Prof. Michael Van Stipdonk, Wichita State University, Department of Chemistry, Wichita, KS 67260-0051, USA. E-mail: mike.vanstipdonk@wichita.edu

* Present address: Department of Chemistry and Biochemistry, Northern Illinois University, DeKalb, IL 60115. scrambling of peptide fragment ions [16]. In the present study, we investigated the tendency for sequence scrambling to occur during collision-induced dissociation (CID) of $b_{n}$ ions of varying sequence and size (3 to 9 amino acid residues). In our experiments, two observations/criteria were used to identify cases in which scrambling of sequence is pronounced: (1) apparent elimination of internal residues from $b_{n}{ }^{+}$and (2) the similarity of fragmentation patterns for peptides with a given size and their permuted isomers.

\section{Experimental}

\section{Peptide Synthesis and Preparation}

All peptides were prepared by conventional solid-phase synthesis methods [18] using 9-fluorenylmethoxycarbonyl (Fmoc) amino acid loaded Wang resin and a custombuilt, multiple reaction vessel peptide synthesis apparatus: sequences were confirmed using multiple-stage $\mathrm{CID}$ of $\mathrm{Na}^{+}$and $\mathrm{Ag}^{+}$cationized versions [19]. Solutions of each peptide were prepared by dissolving the appropriate amount of solid material in a 1:1 (vol:vol) mixture of high-performance liquid chromatography grade $\mathrm{MeOH}$ (Aldrich Chemical, St. Louis, MO, USA) and deionized $\mathrm{H}_{2} \mathrm{O}$, to produce final concentrations of $10^{-5}$ to $10^{-4} \mathrm{M}$.

\section{Mass Spectrometry}

All electrospray ionization (ESI) mass spectra were collected using a Finnigan LCQ-Deca ion-trap mass spectrometer (ThermoFinnigan, San Jose, CA, USA). Peptide solutions were infused into the ESI-MS instrument using the incorporated syringe pump at a flow rate of $5 \mu \mathrm{L} / \mathrm{min}$. The atmospheric pressure ionization stack settings for the LCQ (lens voltages, quadrupole, and octapole voltage offsets, etc.) were optimized for maximum $(\mathrm{M}+\mathrm{H})^{+}$ transmission to the ion trap mass analyzer by using the 


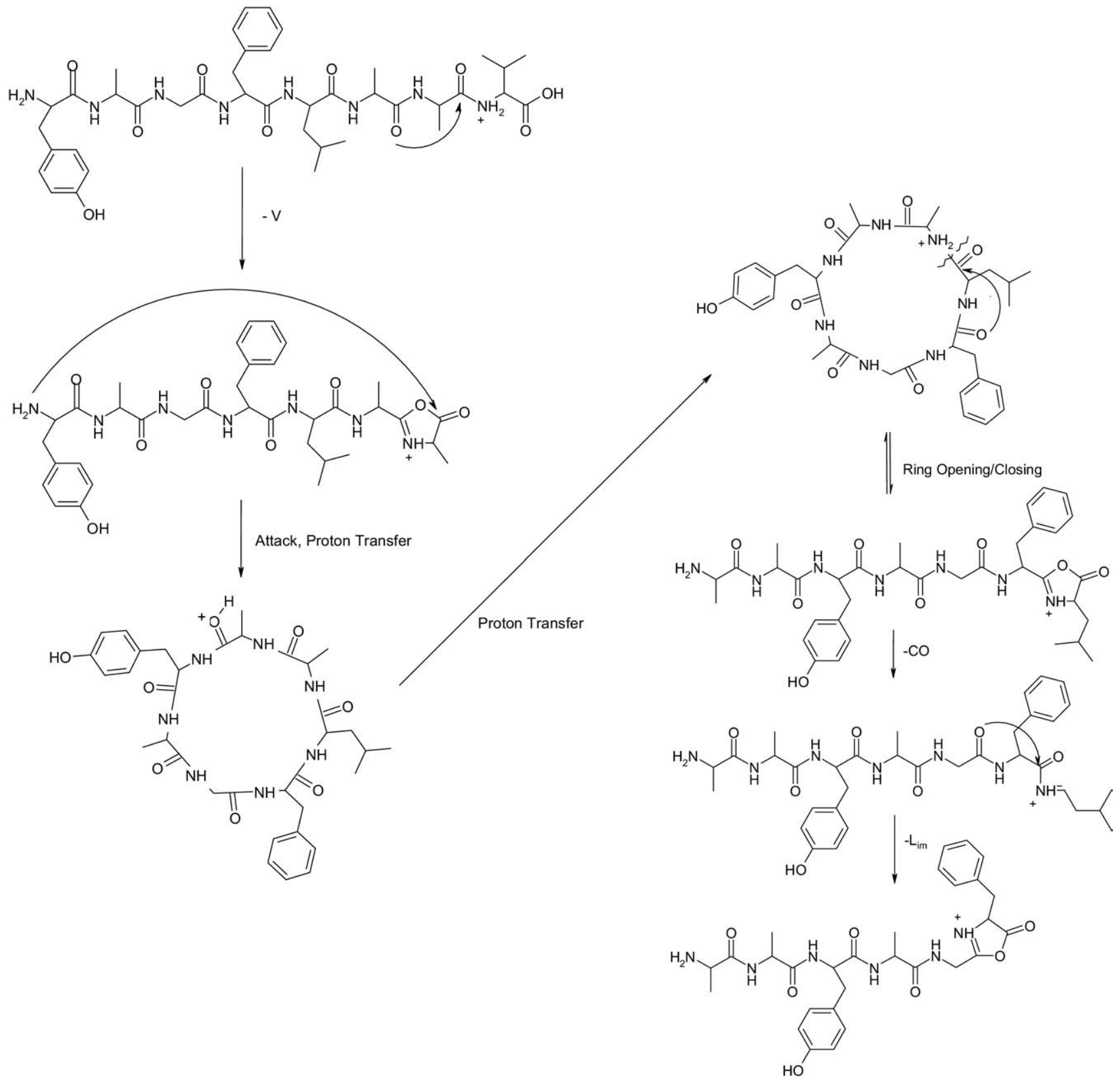

Scheme 1. The reaction mechanism shown illustrates $b$-type scrambling for an octapeptide (YAGFLAAV) from the CID of the $b_{7}$ ion. After CID of the $b_{7}$ ion (YAGFLAA oxa ), the reaction cascade begins with the formation of the macro-ring (cyclo-YAGFLAA), then to the subsequent losses of CO and $\mathrm{L}$ imine, and the sequence is rearranged to form $\mathrm{AAYAGF}_{\text {oxa }}$ ).

auto-tune routine within the LCQ Tune program. Helium was used as the bath/buffer gas to improve trapping efficiency and as the collision gas for CID experiments.

The $(\mathrm{M}+\mathrm{H})^{+}$ions were isolated for the initial CID stage (MS/MS) using an isolation width of 1.0 to 1.5 mass to charge $(\mathrm{m} / \mathrm{z})$ units. Product ions selected for subsequent CID (MS ${ }^{n}$ experiments) were isolated using widths of $1.0-1.3 \mathrm{~m} / \mathrm{z}$ units. The (mass) normalized collision energy was set between 20 and $25 \%$, which (using the current instrument calibration) corresponds roughly to $0.55-0.68 \mathrm{~V}$ applied to the end-cap electrodes to induce collisional activation. The activation $Q$, as labeled by the instrument manufacturer and used to adjust the frequency of the applied radiofrequency collision voltage, was set at 0.30 . Subsequent CID stages were performed using similar activation parameter settings. The activation time used at each CID stage was $30 \mathrm{~ms}$.

\section{Results and Discussion}

\section{Scrambling of $b_{n}$ Ions}

The peptides used in this study included amino acids without acidic or basic side chains, which might be 
expected to influence the tendency for $b_{n}$ ions to cyclize, or reopen upon cyclization. This is because the side chains of amino acids such as aspartic acid and glutamic acid, asparagined, glutamine, and lysine feature nucleophiles that may initiate intramolecular attack and rearrangement. In addition, the side chains of lysine and arginine are basic and may sequester a mobile proton and thus affect the cyclization reaction. Investigation of the influence of these specific residues on cyclization and apparent scrambling is currently under way and will be reported at a later date. Our focus here was on the general influence of fragment size on the tendency to cyclize via a "head-to-tail" process proposed in earlier reports $[16,20]$.

In previous studies, $b_{n}$-type scrambling was evident by both the similarity of product ion distributions for $b$ ions derived from precursor peptides and their permuted isomers, and the apparent elimination of internal residues to furnish smaller $b$ - and $a$-type ions [16, 20]. Fragmentation data for the group of peptides used and $b_{n}{ }^{+}$ions subjected to CID in the present study [tetrapeptides $\left(b_{3}\right)$, pentapeptides $\left(b_{4}\right)$, pentapeptide amides $\left(b_{5}\right)$, heptapeptides $\left(b_{6}\right)$, octapeptides $\left(b_{7}\right)$, octapeptide methyl esters $\left(b_{8}\right)$, decapeptides $\left(b_{9}\right)$, and a decapeptide methyl ester $\left.\left(b_{10}\right)\right]$, precursor ion $m / z$ values, as well as the dominant product ions generated from the largest $b$ ion from each, are provided in Table 1 and 2. CID of $b_{5}{ }^{+}$ from pentapeptide amides was discussed in an earlier report [20] and is included in Table 1 for comparison. Fragmentation of the $b_{2}$ ions derived from tripeptides was not investigated because the elimination of one or the other of the two remaining residues make up the Nand C-terminus of the fragment, and loss of either can be rationally explained using existing fragmentation models and without invoking the formation of macrocyclic products and sequence scrambling.

CID spectra of $b_{3}{ }^{+}$derived from YAFG, AFYG, FAYG, and FYAG are available in Figure S1 of the supplemental material, which can be found in the electronic version of this article. CID of $b_{3}{ }^{+}$produced primarily $a_{3}{ }^{*}(337 \mathrm{~m} / \mathrm{z})$, through loss of 45 mass units ( $u$, corresponding to $\mathrm{CO}$ and $\mathrm{NH}_{3}$ ). The most abundant product ion generated from FYAG was instead $b_{2}{ }^{+}$. The product ions generated from decomposition of each of the $b_{3}{ }^{+}$ions (Table 1 ) are consistent with those expected along the conventional $b_{n}-a_{n}$ pathways, i.e., $b_{3}{ }^{+} \rightarrow a_{3}{ }^{+}$ and $b_{3}{ }^{+} \rightarrow b_{2}{ }^{+}$, and so forth. In addition, the CID spectra generated from each of the $b_{3}{ }^{+}$species are unique to the respective sequences and elimination of internal residues to make smaller $b$-type ions is not observed. Therefore, using these above-cited criteria we can conclude that scrambling of sequence during CID of $b_{3}{ }^{+}$does not occur.

CID spectra of $b_{4}{ }^{+}$generated from YAGFG, FYAGG, GFYAG, and AGFYG (Figure 1) demonstrated the first evidence of scrambling. Fragmentation of $b_{4}{ }^{+}$for all

Table 1. Main fragment ions observed from respective $b_{n}$ ions $^{\mathrm{a}}$

\begin{tabular}{|c|c|}
\hline Peptide group (length) & Fragment ions (assignment) \\
\hline Tetrapeptides & CID of $b_{3}{ }^{+}$ \\
\hline YAFG & $337\left(\mathrm{a}_{\mathbf{3}}{ }^{*+}\right), 235\left(b_{2}^{+}\right), 120\left(\mathrm{~F}_{\mathrm{im}}^{+}\right)$ \\
\hline FYAG & $337\left(a_{3}^{*+}\right), 311\left(\mathbf{b}_{2}^{+}\right)$ \\
\hline AFYG & $337\left(\mathrm{a}_{3}{ }^{*+}\right), 311\left(\mathrm{FY}_{\mathrm{oxa}}{ }^{+}\right), 219\left(b_{2}^{+}\right), 136\left(\mathrm{Y}_{\mathrm{m}}{ }^{+}\right)$ \\
\hline FAYG & $337\left(\mathbf{a}_{\mathbf{3}}^{*+}\right), 219\left(b_{2}^{+}\right), 136\left(\mathrm{Y}_{\mathrm{m}}^{+}\right)$ \\
\hline Pentapeptides & CID of $b_{4}^{+}$ \\
\hline YAGFG & 411 $\left(\mathbf{a}_{4}^{+}\right), 394\left(a_{4}{ }^{*+}\right), 368\left(\mathrm{GFY}_{\text {oxa }}\right), 292\left(\mathrm{YAG}_{\mathrm{oxa}}\right), 276\left(\mathrm{AGF}_{\mathrm{oxa}}\right)$ \\
\hline FYAGG & $411\left(\mathbf{a}_{4}{ }^{+}\right), 394\left(a_{4}{ }^{*+}\right), 368\left(\mathrm{GFY}_{\text {oxa }}\right), 292\left(\mathrm{YAG}_{\text {oxa }}\right), 276\left(\mathrm{AGF}_{\text {oxa }}\right)$ \\
\hline GFYAG & $411\left(\mathrm{a}_{4}{ }^{+}\right), 394\left(a_{4}{ }^{*+}\right), 368\left(\mathrm{GFY}_{\text {oxa }}\right), 292\left(\mathrm{YAG}_{\text {oxa }}\right), 276\left(\mathrm{AGF}_{\text {oxa }}\right)$ \\
\hline AGFYG & $411\left(\mathbf{a}_{\mathbf{4}}^{+}\right), 394\left(a_{4}{ }^{*+}\right), 368\left(\mathrm{GFY}_{\text {oxa }}\right), 292\left(\mathrm{YAG}_{\text {oxa }}\right), 276\left(\mathrm{AGF}_{\text {oxa }}\right)$ \\
\hline Pentapeptide amides & CID of $b_{5}^{+}$ \\
\hline YAGFL-NH ${ }_{2}$ & $534\left(-\mathrm{H}_{2} \mathrm{O}\right), \mathbf{5 2 4}\left(\mathrm{a}_{5}{ }^{+}\right), 507\left(a_{5}{ }^{*+}\right), 481\left(\mathrm{GFLY}_{\text {oxa }}\right), 439\left(\mathrm{YAGF}_{\text {oxa }}\right), 389\left(\mathrm{AGFL}_{\text {oxa }}\right)$ \\
\hline LYAGF-NH 2 & $534\left(-\mathrm{H}_{2} \mathrm{O}\right), \mathbf{5 2 4}\left(\mathrm{a}_{5}{ }^{+}\right), 507\left(a_{5}{ }^{*+}\right), 481\left(\mathrm{GFLY}_{\text {oxa }}\right), 439\left(\mathrm{YAGF}_{\text {oxa }}\right), 389\left(\mathrm{AGFL}_{\text {oxa }}\right)$ \\
\hline FLYAG-NH ${ }_{2}$ & $534\left(-\mathrm{H}_{2} \mathrm{O}\right), \mathbf{5 2 4}\left(\mathrm{a}_{5}{ }^{+}\right), 507\left(a_{5}{ }^{*+}\right), 481\left(\mathrm{GFLY}_{\text {oxa }}\right), 439\left(\mathrm{YAGF}_{\text {oxa }}\right), 389\left(\mathrm{AGFL}_{\text {oxa }}\right)$ \\
\hline GFLYA-NH ${ }_{2}$ & $534\left(-\mathrm{H}_{2} \mathrm{O}\right), \mathbf{5 2 4}\left(\mathrm{a}_{5}^{+}\right), 507\left(a_{5}{ }^{*+}\right), 481\left(\mathrm{GFLY}_{\text {oxa }}\right), 439\left(\mathrm{YAGF}_{\text {oxa }}\right), 389\left(\mathrm{AGFL}_{\text {oxa }}\right)$ \\
\hline AGFLY-NH & $534\left(-\mathrm{H}_{2} \mathrm{O}\right), 524\left(\mathrm{a}_{5}{ }^{+}\right), 507\left(a_{5}^{*+}\right), 481\left(\mathrm{GFLY}_{\text {oxa }}\right), 439\left(\mathrm{YAGF}_{\text {oxa }}\right), 389\left(\mathrm{AGFL}_{\text {oxa }}\right)$ \\
\hline Heptapeptides & CID of $b_{6}^{+}$ \\
\hline YAGFLVG & $\begin{array}{l}633\left(-\mathrm{H}_{2} \mathrm{O}\right), 623\left(\mathrm{a}_{6}{ }^{+}\right), 606\left(a_{6}{ }^{*+}\right), 580\left(\mathrm{GFLVY}_{\text {oxa }}\right), 552\left(\mathrm{YAGFL}_{\text {oxa }}\right), 538\left(\mathrm{VYAGF}_{\text {oxa }}\right), 488\left(\mathrm{AGFLV}_{\text {oxa }}\right) \text {, } \\
\quad 417\left(\mathrm{GFLV}_{\text {oxa }}\right)\end{array}$ \\
\hline VYAGFLG & $\begin{array}{l}633\left(-\mathrm{H}_{2} \mathrm{O}\right), 623\left(\mathrm{a}_{6}{ }^{+}\right), 606\left(a_{6}{ }^{*+}\right), 580\left(\mathrm{GFLVY}_{\text {oxa }}\right), 552\left(\mathrm{YAGFL}_{\text {oxa }}\right), 538\left(\mathrm{VYAGF}_{\text {oxa }}\right), 488\left(\mathrm{AGFLV}_{\text {oxa }}\right), \\
\quad 417\left(\mathrm{GFLV}_{\text {oxa }}\right)\end{array}$ \\
\hline LVYAGFG & $\begin{array}{l}633\left(-\mathrm{H}_{2} \mathrm{O}\right), 623\left(\mathrm{a}_{6}{ }^{+}\right), 606\left(a_{6}{ }^{*+}\right), 580\left(\mathrm{GFLVY}_{\text {oxa }}\right), 552\left(\mathrm{YAGFL}_{\text {oxa }}\right), 538\left(\mathrm{VYAGF}_{\text {oxa }}\right), 488\left(\mathrm{AGFLV}_{\text {oxa }}\right), \\
\quad 417\left(\mathrm{GFLV}_{\text {oxa }}\right)\end{array}$ \\
\hline FLVYAGG & $\begin{array}{l}633\left(-\mathrm{H}_{2} \mathrm{O}\right), 623\left(\mathrm{a}_{6}{ }^{+}\right), 606\left(a_{6}{ }^{*+}\right), 580\left(\mathrm{GFLVY}_{\text {oxa }}\right), 552\left(\mathrm{YAGFL}_{\text {oxa }}\right), 538\left(\mathrm{VYAGF}_{\text {oxa }}\right), 488\left(\mathrm{AGFLV}_{\text {oxa }}\right), \\
\quad 417\left(\mathrm{GFLV}_{\text {oxa }}\right)\end{array}$ \\
\hline GFLVYAG & $\begin{array}{l}633\left(-\mathrm{H}_{2} \mathrm{O}\right), 623\left(\mathrm{a}_{6}{ }^{+}\right), 606\left(a_{6}{ }^{*+}\right), 580\left(\mathrm{GFLVY}_{\text {oxa }}\right), 552\left(\mathrm{YAGFL}_{\text {oxa }}\right), 538\left(\mathrm{VYAGF}_{\text {oxa }}\right), 488\left(\mathrm{AGFLV}_{\text {oxa }}\right), \\
\quad 417\left(\mathrm{GFLV}_{\text {oxa }}\right)\end{array}$ \\
\hline AGFLVYG & $\begin{array}{l}633\left(-\mathrm{H}_{2} \mathrm{O}\right), 623\left(\mathrm{a}_{6}{ }^{+}\right), 606\left(a_{6}{ }^{*+}\right), 580\left(\mathrm{GFLVY}_{\text {oxa }}\right), 552\left(\mathrm{YAGFL}_{\text {oxa }}\right), 538\left(\mathrm{VYAGF}_{\text {oxa }}\right), 488\left(\mathrm{AGFLV}_{\text {oxa }}\right), \\
\quad 417\left(\mathrm{GFLV}_{\text {oxa }}\right)\end{array}$ \\
\hline
\end{tabular}

apeptides separated into subgroups (tetrapeptide through heptapeptide) based on amino acid chain length. 
Table 2. Main fragment ions observed from respective $b_{n}$ ions $^{\mathrm{a}}$

\begin{tabular}{|c|c|}
\hline Peptide group (length) & Fragment ions (assignment) \\
\hline Octapeptides & $\mathrm{CID}$ of $b_{7}^{+}$ \\
\hline YAGFLAAV & 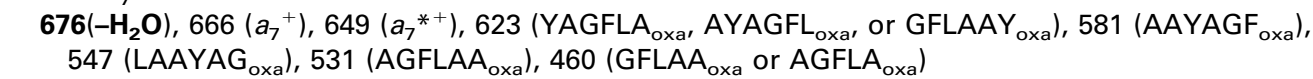 \\
\hline FLYAGAAV & 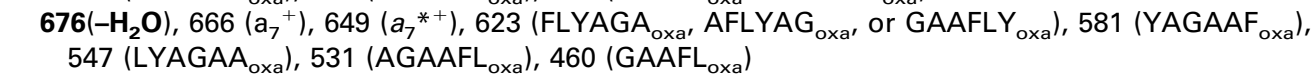 \\
\hline Octapeptide methyl esters & CID of $b_{8}^{+}$ \\
\hline YAGFLAAV-OMe & 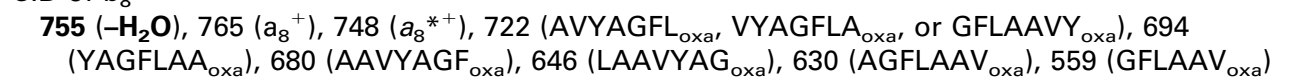 \\
\hline FLYAGAAV-OMe & $\begin{array}{l}755\left(-\mathrm{H}_{2} \mathrm{O}\right), 765\left(a_{8}{ }^{+}\right), 748\left(a_{8}{ }^{*+}\right), 722\left(\mathrm{GAAVFLY}_{\text {oxa }}, \text { VFLYAGA }_{\text {oxa }} \text { or } \text { AVFLYAG }_{\text {oxa }}\right), 694 \\
\left(\mathrm{FLYAGAA}_{\text {oxa }}\right), 680\left(\mathrm{YAGAAVF}_{\text {oxa }}\right), 646\left(\mathrm{LYAGAAV}_{\text {oxa }}\right), 630\left(\mathrm{AGAAVFL}_{\text {oxa }}\right), 559\left(\mathrm{GAAVFL}_{\text {oxa }}\right), \\
533\left(\mathrm{YAGAAV}_{\text {oxa }}\right)\end{array}$ \\
\hline Decapeptides & CID of $b_{9}^{+}$ \\
\hline YAGFLYAGFL & 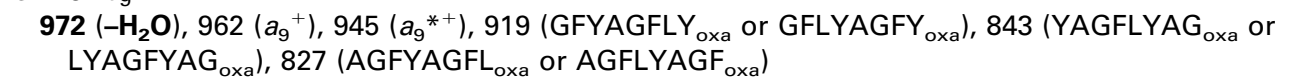 \\
\hline FLYAGFLYAV & 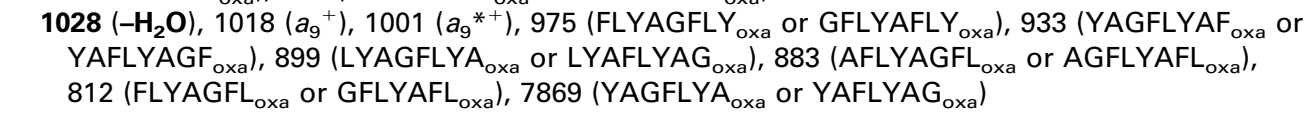 \\
\hline $\begin{array}{l}\text { Decapeptide methyl ester } \\
\text { YAGFLYAGFL-OMe }\end{array}$ & 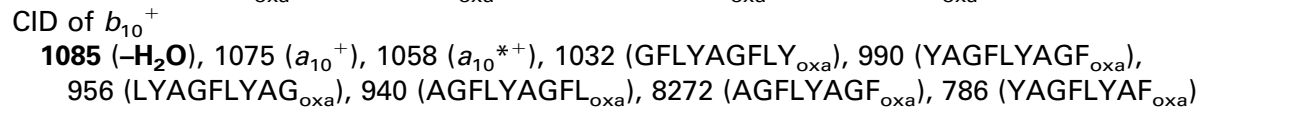 \\
\hline
\end{tabular}

aPeptides separated into subgroups (octapeptide through decapeptide methyl ester) based on amino acid chain length.

four of the pentapeptides yielded a dominant $a_{4}$ ion at $\mathrm{m} / \mathrm{z} 411$ and product ions at $\mathrm{m} / \mathrm{z} 394,368,292$, and 276. The $\mathrm{m} / \mathrm{z} 394$ corresponds to the $a_{4}{ }^{*}$ ion $(-45 \mathrm{u})$. The $\mathrm{m} / \mathrm{z}$ 368,292 , and 276 peaks correspond to elimination of A $(-71 \mathrm{~m} / \mathrm{z}), \mathrm{F}(-147 \mathrm{~m} / \mathrm{z})$, and $\mathrm{Y}(-163 \mathrm{~m} / \mathrm{z})$, respectively. One or more of these amino acids are internal residues for the permuted sequence isomers of YAGFG, and thus the similarity of the spectra and distribution of product ions suggest that $b$-type scrambling is occurring [20]. In addition, neutral losses corresponding to the residue masses of $\mathrm{Y}, \mathrm{F}$, and A from YAGFL, FYAGG, and AGFYG, respectively, are difficult to rationalize without invoking formation and reopening of a macrocylic $b_{4}$ ion, and the resulting scrambling of sequence. Fragmentation reactions in which portions of the $\mathrm{N}$-terminal amino acid are eliminated more commonly involve loss of the imine mass of the residue along the $a_{n} / y_{m}$ pathway [14].

The only major difference between the spectra displayed in Figure 1 is the higher abundance of the $\mathrm{m} / \mathrm{z}$ 368 (loss of A) peak in the CID spectrum generated from $b_{4}{ }^{+}$initially derived from GFYAG. The reason for the apparent favored loss of A from this peptide is not known. Detailed investigation of the relative energetics of ring formation and opening using density functional theory, which is beyond the scope of this report, would certainly provide additional insight. In any case, the qualitative similarity of the spectra in Figure 1 and the observed loss of internal residues strongly suggest that scrambling of $b_{4}{ }^{+}$occurs for these peptides.

The apparent scrambling was observed regardless of the specific linkages of amino acids within the peptide. The peptides used to produce the data in Figure 1 bear common peptide bonds. For example, three of the four have $\mathrm{F}$ to the $\mathrm{N}$-terminal side of $\mathrm{Y}$ and $\mathrm{Y}$ to the
N-terminal side of A. Peptides with additional sequences and, in particular, different amide linkages were synthesized and subjected to CID. Loss of internal residues was still observed for $b_{4}{ }^{+}$derived from ALFGG and GALFG (Figure S2a and b of the supplemental material). The tendency for the loss of $\mathrm{A}$ or $\mathrm{F}$ from either ALFGG or GALFG differed somewhat compared with the peptides used to produce the data in Figure 1. This is not unexpected, given that the probability for generating a particular product ion is expected to depend on the strengths of amide bonds and the relative energies of products based on the PIC model of peptide dissociation [14].

The CID spectra $\left(\mathrm{MS}^{4}\right.$ stage) generated from the respective $a_{4}{ }^{+}$ions derived from the permuted sequence isomers of YAGFG were also nearly identical (spectra not shown). In a prior study of apparent sequence scrambling, the similarity of CID spectra from $a_{n}{ }^{+}$ions from permuted sequence isomers was rationalized by assuming prior scrambling of $b_{n}{ }^{+}$ions, and the fact that $a$-type ions are primarily formed from $b$ fragments by loss of $\mathrm{CO}$. In other words, scrambling at the level of $a_{n}{ }^{+}$ions need not be invoked [20].

The results reported here using $b_{4}{ }^{+}$from the permuted YAGFG isomers are interesting when compared with a previous study by Polfer and colleagues [21] of the structure of $b_{4}{ }^{+}$generated from protonated YAGFL. Using infrared multiple-photon dissociation (IRMPD) spectroscopy, it was determined that $b_{4}{ }^{+}$has an oxazolone structure. Our results strongly suggest that sequence scrambling occurs for the $b_{4}{ }^{+}$ions generated from the YAGFG group of peptides, presumably through a macrocyclic intermediate. We note that in the prior investigation of apparent scrambling of $b_{5}{ }^{+}$from YAGFL $-\mathrm{NH}_{2}$ and related peptides [20], it was suggested that the macrocy- 


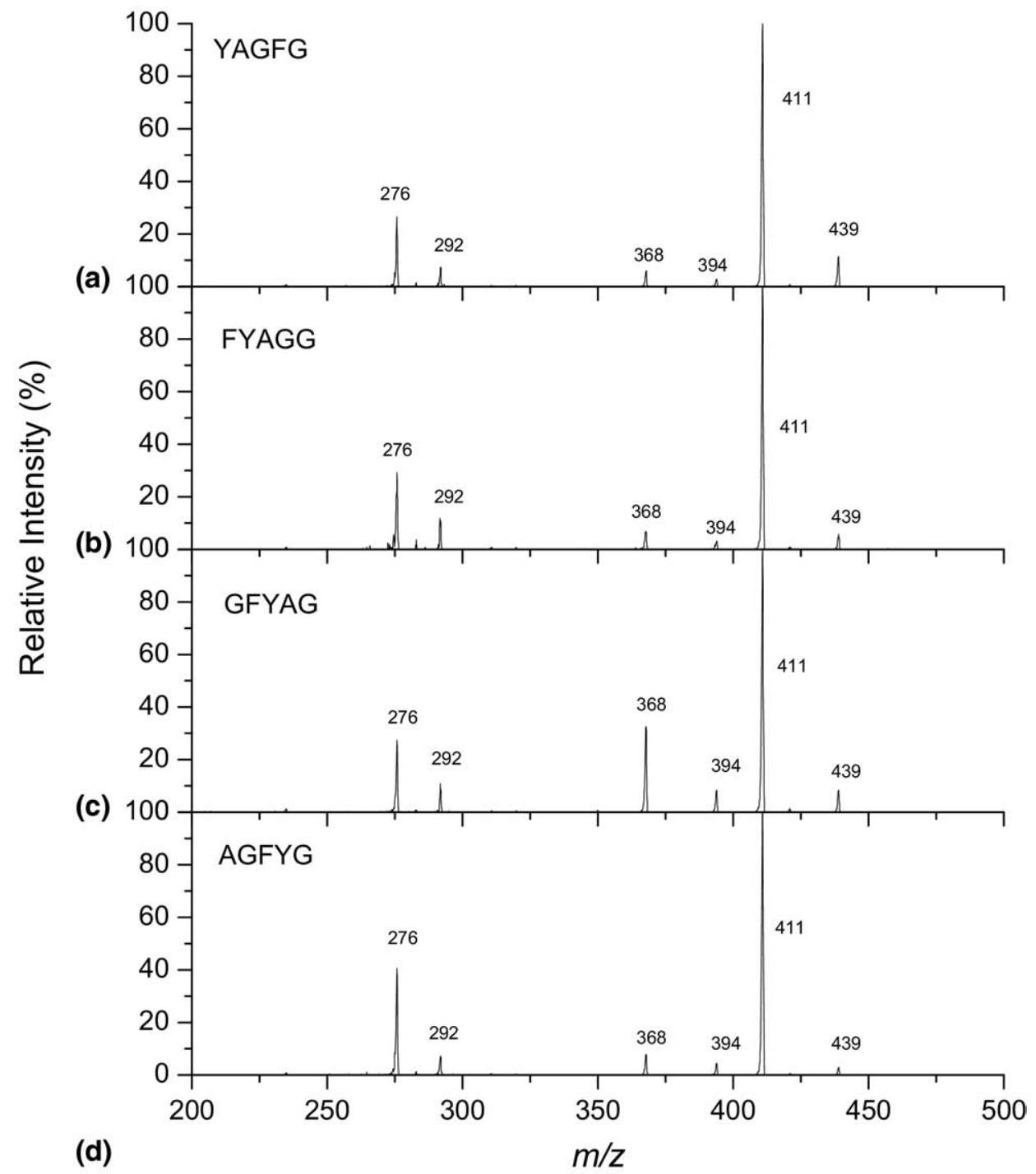

Figure 1. CID of $b_{4}{ }^{+}\left(\mathrm{MS}^{3}\right.$ of sequence isomers of the protonated pentapeptide YAGFG. Sequences of each precursor peptide are shown with their respective spectra: (a) CID (MS ${ }^{3}$ of $b_{4}{ }^{+}$from YAGFG, (b) CID (MS ${ }^{3}$ of $b_{4}{ }^{+}$from FYAGG, (c) CID (MS ${ }^{3}$ of $b_{4}{ }^{+}$from GFYAG, (d) CID (MS ${ }^{3}$ of $b_{4}{ }^{+}$from AGFYG.

clic isomer can open at various amide positions to regenerate linear, oxazolone-terminated structures: this is necessary to cause the elimination of internal residues. It may be that the structure probed in the earlier IRMPD study was a linear, oxazolone structure resulting from the opening of the macrocyclic ring.

The data in Tables 1 and 2 show that sequence scrambling also occurs for the other $b_{n}$ ions $\left(b_{5}, b_{6}, b_{7}, b_{8}\right.$, $b_{9}$, and $b_{10}$ ) included in this study. Similar product ion distributions (including ions that are the result of the elimination of internal residues) are observed within each set of $b_{n}$ subjected to CID. This fact is clearly evident in the spectra for the heptapeptides shown in Figure 2. The dominant product ion for each of the six heptapeptides is the $a_{6}$ ion with $\mathrm{m} / \mathrm{z} 623(-28 \mathrm{~m} / \mathrm{z})$. Other product ions include those at $m / z$ 633, 606, 580, $552,538,488$, and 417 . The $m / z 633$ ion represents the loss of water $(-18 \mathrm{~m} / \mathrm{z})$ and $\mathrm{m} / \mathrm{z} 606$ is the $a_{6}{ }^{*}$ ion $(-45$ mass units). The product ions at $m / z 580,552,538$, and 488 correspond to the loss of single amino acid residues A $(-71 \mathrm{~m} / \mathrm{z}), \mathrm{V}(-99 \mathrm{~m} / \mathrm{z}), \mathrm{L}(-113 \mathrm{~m} / \mathrm{z})$, and Y $(-163$ $m / z)$, respectively, whereas the $m / z 417$ corresponds to the loss of the two adjacent amino acid residues YA $(-234 \mathrm{~m} / \mathrm{z})$ : one or more of the observed neutral losses involved elimination of internal amino acid residues from $b_{6}{ }^{+}$, thus indicating the apparent scrambling of sequence. In addition, as with the case for all the other $b_{n}$ ions starting with $b_{4}{ }^{+}$, the CID patterns for the range of $b_{6}$ ions are remarkably similar.

As for the $b_{4}{ }^{+}$ions discussed earlier, a group of peptides with alternative amino acid linkages were synthesized to check the general loss of internal residues from $b_{5}{ }^{+}$and $b_{6}{ }^{+}$. As shown in Figures S2 and S3 of the supplemental material, loss of internal residuesand thus apparent scrambling of sequence-was observed for $b_{5}{ }^{+}$generated from ALFGG-OMe and 


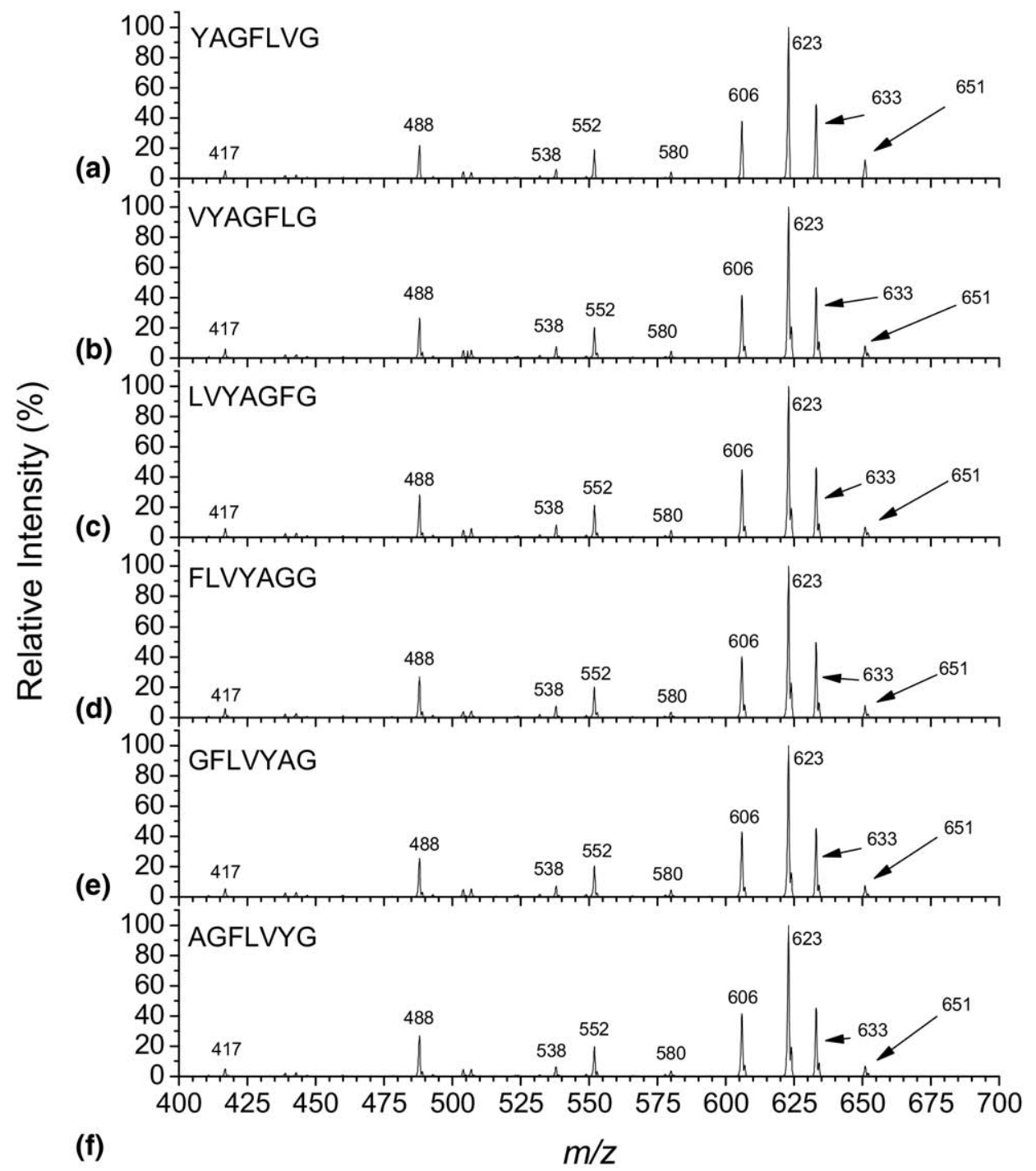

Figure 2. $\mathrm{CID}$ of $b_{6}{ }^{+}\left(\mathrm{MS}^{3}\right.$ of sequence isomers of the protonated heptapeptide YAGFLVG. Sequences of each precursor peptide are shown with their respective spectra: (a) CID (MS ${ }^{3}$ of $b_{6}{ }^{+}$from YAGFLVG, (b) CID (MS ${ }^{3}$ of $b_{6}{ }^{+}$from VYAGFLG, (c) CID $\left(\mathrm{MS}^{3}\right.$ of $b_{6}{ }^{+}$from LVYAGFG, (d) CID (MS ${ }^{3}$ of $b_{6}{ }^{+}$from FLVYAGG, (e) CID (MS ${ }^{3}$ of $b_{6}{ }^{+}$from GFLVYAG, (f) CID (MS ${ }^{3}$ of $b_{6}{ }^{+}$from AGF LVYG.

GALFG-OMe (Figure S2c and d, respectively). Similar results were observed for $b_{5}{ }^{+}$generated from GAFYLG and LFYAGG (Figure S2a and b, respectively), and for $b_{6}{ }^{+}$generated from the methyl esters of the same peptides (Figure S3c and d, respectively).

An interesting trend observed is that intensity of the $a_{n}{ }^{+}$ion decreases whereas the loss of $\mathrm{H}_{2} \mathrm{O}$ increases, with increasing peptide $/ b_{n}{ }^{+}$ion size, as is apparent in Figure 3. The loss of $\mathrm{H}_{2} \mathrm{O}$ from protonated peptides was previously investigated by Reid et al. [22], who proposed that the reaction involves elimination of the oxygen atom from the C-terminal- $\mathrm{OH}$ group or the amide group via a retroRitter-type pathway. For the $b_{n}{ }^{+}$ions investigated here, there is no C-terminal- $\mathrm{OH}$ to furnish the $\mathrm{H}_{2} \mathrm{O}$ neutral loss. Therefore, it is more likely that the retro-Ritter-type reaction is responsible. It is not yet known whether the $a_{n}{ }^{+}$ pathway becomes more unstable or whether the loss of
$\mathrm{H}_{2} \mathrm{O}$ becomes more favored because of the changes in configuration (such as secondary or tertiary structure effects) or more complex hydrogen bonding, as the length of the peptide increases in size.

\section{Conclusions}

To summarize, the objective of this study was to determine whether apparent sequence scrambling occurs during CID of $b_{n}{ }^{+}$of differing size. Our results demonstrated that for the tetrapeptide YAFG and its isomers, nondirect sequence ions were not formed from the dissociation of the $b_{3}$ ion. This may be attributable to potential extensive steric strain after cyclization. However, scrambling of the $b_{n}{ }^{+}$ion does occur for the remaining peptides (pentapeptides to the decapeptide methyl esters) included in the study. For the larger 


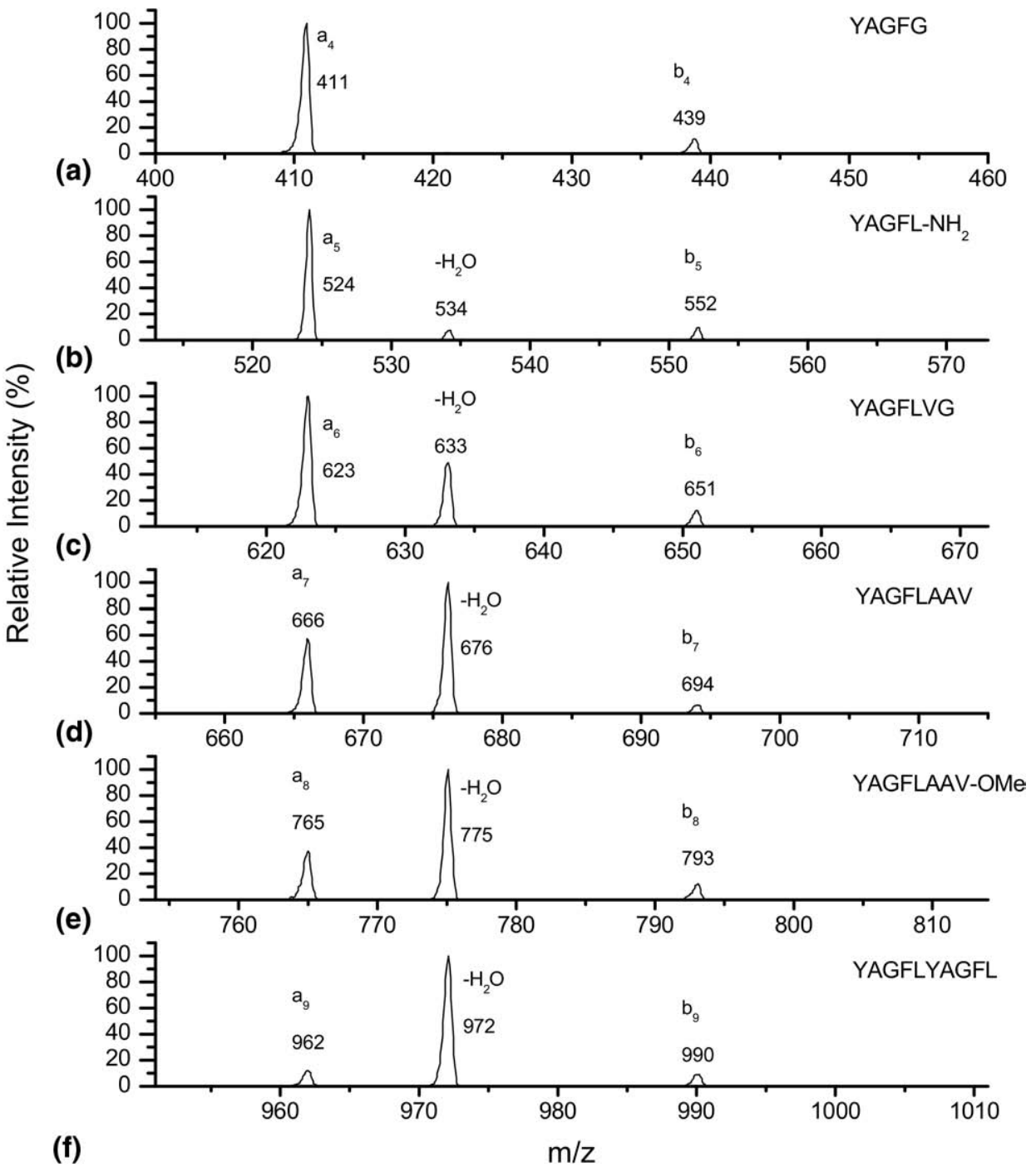

Figure 3. Comparison of loss of $\mathrm{H}_{2} \mathrm{O}$ and formation of $a_{n}{ }^{+}$from the CID of $b_{n}{ }^{+}$(MS $^{3}$ of peptides (a) YAGFG, (b) YAGFL-NH ${ }_{2}$, (c) YAGFLVG, (d) YAGFLAAV, (e) YAGFLAAV-OMe, (f) YAGFLYAGFL.

peptides (i.e., hepta-, octa-, nonapeptides, etc.), the "scrambling" of $b$-type ions would seem unlikely because the increase in size, conformational space that can be accessed, and degrees of freedom would make formation of the macrocycle entropically disfavored. However, the results of the study clearly establish the loss of sequence and are consistent with earlier reports of sequence scrambling for the larger $b$ ions and are for $b_{5}{ }^{+}[16,20]$ and larger $b$-type ions [17].

We note that the apparent scrambled $b_{n}$ ions do not contribute significantly to the product ion distribution(s) generated from the respective protonated precursor peptides (spectra not shown), thus suggesting that the influence of the cyclization reactions in the interpretation of CID patterns from $(\mathrm{M}+\mathrm{H})^{+}$may be minimal. However, the issue of scrambling will certainly be important in $\mathrm{MS}^{n}$ experiments, such as those reported by Olsen and Mann [23], in which N-terminuscontaining peptide fragments generated by CID were difficult to rationalize using conventional models of peptide fragmentation.

\section{Acknowledgments}

This work was supported the National Science Foundation (CAREER-0239800). SO thanks Wichita State University for support of her undergraduate research and SM acknowledges Hospira, Inc. for financial support of his graduate research. The authors also thank Bela Paizs, Alex Harrison, Christian Bleiholder, and Ben Bythell for helpful discussions.

\section{Appendix A Supplementary Material}

Supplementary material associated with this article may be found in the online version at doi:10.1016/ j.jasms.2009.07.023. 


\section{References}

1. Hunt, D. F.; Yates, J. R., 3rd; Shabanonowitz, J.; Winston, S.; Hauer, C. R. Protein Sequencing by Tandem Mass Spectrometry. Proc. Natl. Acad. Sci. U.S.A. 1986, 83, 6233-6237.

2. Biemann, K. Contributions of Mass Spectrometry to Peptide and Protein Structure. Biomed. Environ. Mass Spectrom. 1988, 16, 99-111.

3. Steen, H.; Mann, M. The abc's and the xyz's of Peptide Sequencing. Nat. Rev. Mol. Cell. Biol. 2004, 5, 699-711.

4. Nesvizhskii, A. E.; Vitek, O.; Aebersold, R. Analysis and Validation of Proteomic Data Generated by Tandem Mass Spectrometry. Nat. Methods 2007, 4, 787-797.

5. Roepstroff, P.; Fohlmann, J. Proposal for a Common Nomenclature for Sequence Ions in Mass Spectra of Peptides. J. Biomed. Mass Spectrom. 1984, 11, 601.

6. Papayannopoulis, I. A. The Interpretation of Collision-Induced Dissociation Tandem Mass Spectra of Pepetides. Mass Spectrom. Rev. 1995, 14, 49-73.

7. Dongre, A. R.; Jones, J. L.; Somogyi, A.; Wysocki, V. H. Influence of Peptide Composition, Gas-Phase Basicity, and Chemical Modification on Fragmentation Efficiency: Evidence for the Mobile Proton Model. J. Am. Chem. Soc. 1996, 118, 8365-8374.

8. Wysocki, V. H.; Tsaprailis, G.; Smith, L. L.; Breci, L. A. Mobile and Localized Protons: A Framework for Understanding Peptide Dissociation. J. Mass Spectrom. 2000, 35, 1399-1406.

9. Yalcin, T.; Csizmadia, I. G.; Peterson, M. B.; Harrison, A. Why Are $b$ Ions Stable Species in Peptide Spectra? J. Am. Soc. Mass Spectrom. 1996, 7, 233-242.

10. Paizs, B.; Lendvay, G.; Vekey, K.; Suhai, S. Formation of $b_{2}{ }^{+}$Ions from Protonated Peptides: An Ab Initio Study. Rapid Commun. Mass Spectrom. 1999, 13, 525-533.

11. Paizs, B.; Suhai, S. Towards Understanding the Tandem Mass Spectra of Protonated Oligopeptides. 1: Mechanism of Amide Bond Cleavage. J. Am. Soc. Mass Spectrom. 2004, 15, 103-113.
12. Paizs, B.; Suhai, S. Combined Quantum Chemical and RRKM Modelling of the Main Fragmentation Pathways of Protonated GGG. II. Formation of $\mathrm{b}_{2}, \mathrm{y}_{1}$, and $\mathrm{y}_{2}$ Ions. Rapid Commun. Mass Spectrom. 2002, 16, 375-389.

13. Polce, M. J.; Ren, D.; Wesdemiotis, C. Dissociation of the Peptide Bond in Protonated Peptides. J. Mass Spectrom. 2000, 35, 1391-1398.

14. Paizs, B.; Suhai, S. Fragmentation Pathways of Protonated Peptides. Mass Spectrom. Rev. 2004, 24, 508-548.

15. Yalcin, T.; Khouw, C.; Csizmadia, I. G.; Peterson, M. R.; Harrison, A. G. The Structure and Fragmentation of $b_{n}(n \geq 3)$ Ions in Peptide Spectra. J. Am. Soc. Mass Spectrom. 1995, 6, 1165-1174.

16. Harrison, A. G.; Young, A. B.; Bleiholder, B.; Suhai, S.; Paizs, B. Scrambling of Sequence Information in Collision-induced Dissociation of Peptides. J. Am. Chem. Soc. 2006, 128, 10364-10365.

17. Riba-Garcia, F.; Giles, K.; Bateman, R. H.; Gaskell, S. J. Evidence for Structural Variants of a- and b-Type Peptide Fragment Ions Using Combined Ion Mobility/Mass Spectrometry. J. Am. Soc. Mass Spectrom. 2008, 19, 609-613.

18. Chan, W. C.; White, P. D., eds. Fmoc Solid Phase Peptide Synthesis-A Practical Approach. New York: Oxford University Press; 2000.

19. Barr, J. M.; Van Stipdonk, M. J. Multi-stage Tandem Mass Spectrometry of Metal Cationized Leucine Enkaphlin and Leucine Enkaphlin Amide. Rapid Commun. Mass Spectrom. 2002, 16, 566-578.

20. Bleiholder, C.; Osburn, S.; Williams, T. D.; Suhai, S.; Van Stipdonk, M.; Harrison, A. G.; Paizs, B. Sequence Scrambling Fragmentation Pathways of Protonated Peptides. J. Am. Chem. Soc. 2008, 130, 17774-17789.

21. Polfer, N. C.; Oomens, J.; Suhai, S.; Paizs, B. Spectroscopic and Theoretical Evidence for Oxazolone Ring Formation in Collision-Induced Dissociation. J. Am. Chem. Soc. 2005, 127, 17154-17155.

22. Reid, G. E.; Simpson, R. J.; O'Hair, R. A. J. A Mass Spectrometric and Ab Initio Study of the Pathways for Dehydration of Simple Glycine and Cysteine-containing Peptide $[\mathrm{M}+\mathrm{H}]^{+}$ions. J. Am. Soc. Mass Spectrom. 1998, 9, 945-956.

23. Olsen, J. V.; Mass, M. Improved Peptide Identification in Proteomics by Two Consecutive Stages of Mass Spectrometric Fragmentation. Proc. Natl. Acad. Sci. U.S.A. 2004, 101, 13417-13422. 